06

\title{
Исследование морфологии поверхности и химического состава кремния, имплантированного ионами меди
}

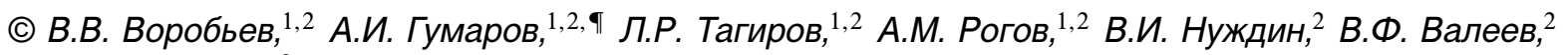 \\ А.Л. Степанов ${ }^{2}$ \\ ${ }^{1}$ Казанский федеральный университет, Институт физики, \\ 420008 Казань, Россия \\ ${ }^{2}$ Казанский фиизико-технический институт им. Е.К. Завойского - \\ обособленное структурное подразделение ФИЦ КазНЦ РАН, \\ 420029 Казань, Россия \\ I e-mail: amir@gumarov.ru
}

Поступило в Редакцию 24 января 2020 г.

В окончательной редакции 12 марта 2020 г.

Принято к публикации 31 марта 2020 г.

Представлены результаты исследований структуры и химического состава поверхности монокристаллических подложек кремния $c-\mathrm{Si}$, имплантированных ионами $\mathrm{Cu}^{+}$с энергией $40 \mathrm{keV}$ и дозами в диапазоне $3.1 \cdot 10^{15}-1.25 \cdot 10^{17}$ ions $/ \mathrm{cm}^{2}$ при плотности тока в ионном пучке $8 \mu \mathrm{A} / \mathrm{cm}^{2}$. Методами сканирующей электронной и зондовой микроскопии в сочетании с рентгеновской фотоэлектронной и ожеэлектронной спектроскопии установлено, что на начальной стадии облучения ионами $\mathrm{Cu}^{+}$до величины дозы $6.25 \cdot 10^{16}$ ions $/ \mathrm{cm}^{2}$, в приповерхностном слое $\mathrm{Si}$ формируются металлические наночастицы $\mathrm{Cu}$ co средним размером $10 \mathrm{~nm}$. При дальнейшем росте дозы имплантации, начиная со значения $1.25 \cdot 10^{17} \mathrm{ions} / \mathrm{cm}^{2}$ и выше, происходит зарождение $\eta$-фазы силицида меди $-\eta$ - $\mathrm{Cu}_{3} \mathrm{Si}$. Данное обстоятельство обусловлено разогревом приповерхностного слоя подложки $\mathrm{Si}$ во время ее облучения до температуры, способствующей фазообразованию $\eta$ - $\mathrm{Cu}_{3} \mathrm{Si}$.

Ключевые слова: высокодозовая ионная имплантация, наночастицы меди, силицид меди.

DOI: $10.21883 /$ JTF.2020.10.49804.31-20

\section{Введение}

На практике, для целенаправленной модификации поверхностных свойств слоев $c$-Si используются различные технологические приемы внедрения или осаждения примеси $\mathrm{Cu}$, которые приводят к изменению морфологии, фазового состава поверхности, а также электрохимических, каталитических, электрических и оптических характеристик Si. К таким технологиям относятся, например, иммерсионное химическое осаждение $\mathrm{Cu}$ из раствора $\mathrm{CuSO}_{4} \cdot 5 \mathrm{H}_{2} \mathrm{O}$ на поверхность плоской пластины или пористого слоя $\mathrm{Si}$ (PSi) [1], приводящее к покрытию Si практически сплошным слоем из наночастиц $\mathrm{Cu}$ размером $\sim 10 \mathrm{~nm}$. Другой подход модификации PSi заключается в электрохимическом осаждении на поверхность образца наночастиц $\mathrm{Cu}$ из коллоидных растворов [2]. В обозначенных работах наблюдалось частичное окисление наночастиц $\mathrm{Cu}$ без образования какой-либо разновидности фазы силицида меди.

Помимо химических способов осаждения $\mathrm{Cu}$ на $\mathrm{Si}$, применяются также и физические методы внедрения примеси металлов, например, ионная имплантация [3]. Известно, что данный подход широко используется в полупроводниковой промышленности при изготовлении электронных устройств [4]. По-видимому, одной из первых работ по имплантации $\mathrm{Si}$ ионами $\mathrm{Cu}^{+}$следует считать работу [5], в которой облучение $\mathrm{Si}$ проводилось относительно малыми дозами $\left(D<5 \cdot 10^{15}\right.$ ions $\left./ \mathrm{cm}^{2}\right)$.

В настоящей работе, с целью оценки возможности контролируемого формирования наночастиц $\mathrm{Cu}$ в $\mathrm{Si}$ методом ионной имплантации были проведены эксперименты по облучению монокристаллической подложки $c$-Si ионами $\mathrm{Cu}^{+}$с энергией $40 \mathrm{keV}$ и различными $D$, а также исследованы особенности изменения структуры и химического состава поверхности облученного $\mathrm{Si}$.

\section{1. Методика эксперимента}

В качестве исходной подложки использовались полированные монокристаллические пластины $c$-Si. Имплантация проводилась ионами $\mathrm{Cu}^{+}$с энергией $E=40 \mathrm{keV}$ и $D$ в диапазоне $3.1 \cdot 10^{15}-1.25 \cdot 10^{17}$ ions $/ \mathrm{cm}^{2}$ при плотности тока в ионном пучке $J=8 \mu \mathrm{A} / \mathrm{cm}^{2}$. Имплантация выполнялась на ионно-лучевом ускорителе ИЛУ-3 при комнатной температуре облучаемых подложек. Структура поверхности образцов исследовалась на сканирующих электронном (scanning electron microscope SEM, Merlin, Carl Zeiss) и зондовом (scanning probe microscope - SPM, Dimension FastScan, Bruker) микроскопах. Элементный анализ выполнялся с помощью энергодисперсионного спектрометра (energy-dispersive X-ray spectrometer - EDX, X-Max, Oxford Instruments), интегрированного в SEM. Исследования химического 

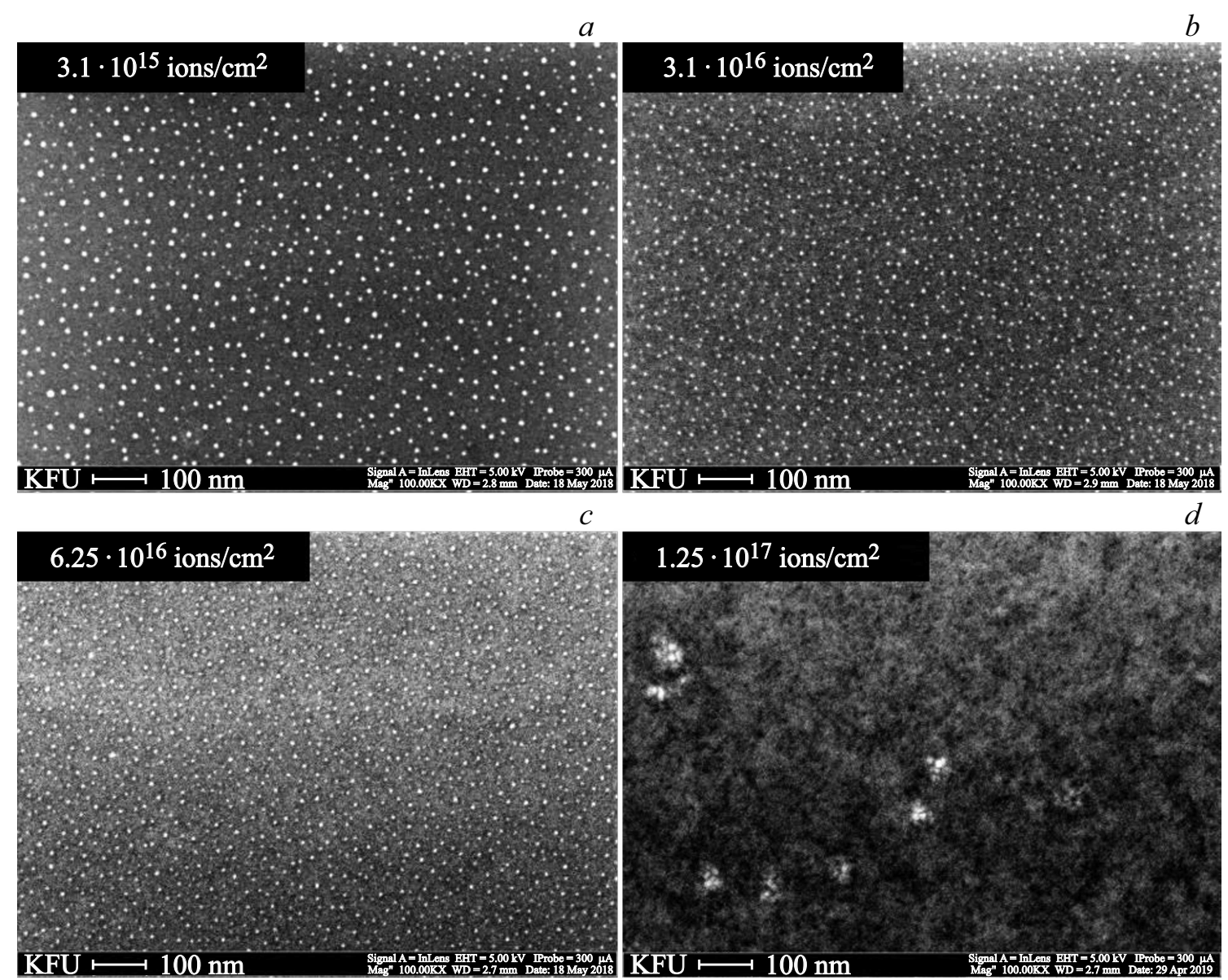

Рис. 1. $\mathrm{SEM-изображения} \mathrm{изменения} \mathrm{поверхности} \mathrm{Si}$, имплантированного ионами $\mathrm{Cu}^{+}$при $E=40 \mathrm{keV}(D$ указана на вставках).

состава образцов и валентного состояния внедренной примеси $\mathrm{Cu}$ в $\mathrm{Si}$ проводились методами рентгеновской фотоэлектронной спектроскопии (X-ray photoelectron spectroscopy - XPS) и оже-электронной (Auger electron spectroscopy - AES) спектроскопии с применением техники профилирования ионами $\mathrm{Ar}^{+}$поверхности образцов. XPS- и AES-исследования выполнялись в сверхвысоковакуумной аналитической камере (SPECS, Германия), оборудованной немонохроматическим источником рентгеновского излучения $\operatorname{Mg} K_{\alpha}$ с энергией фотонов $E=1284.6 \mathrm{eV}$ и полусферическим анализатором энергий электронов SPECS Phoibos 150. Давление остаточных газов в камере во время измерений составляло $5 \cdot 10^{-10}$ mbar. Травление выполнялось ионной пушкой с энергией ускоряющего напряжения $E=1 \mathrm{keV}$ при падении пучка заряженных частиц $\mathrm{Ar}^{+}$под углом $45^{\circ}$ при размере растра $10 \times 10 \mathrm{~mm}^{2}$. XPS-анализ чередовался с ионным травлением с целью исследования валентного состояния примеси $\mathrm{Cu}$ в облученном слое $\mathrm{Si}$ на различной глубине от поверхности. Обзорный XPS-спектр регистрировался с шагом $1 \mathrm{eV}$ и энергией пропускания анализатора $\mathrm{E}=100 \mathrm{eV}$. Подробные XPS- и AES-спектры записывались с шагом $0.1 \mathrm{eV}$ и энергией пропускания 25 и $12 \mathrm{eV}$ соответственно для каждой из методик.
Полученные спектры являлись результатом усреднения по 10-ти сканированиям. Анализ всех зарегистрированных спектров выполнялся при помощи компьютерной программы CasaXPS [6].

\section{2. Результаты и обсуждения}

На рис. 1 представлены SEM-изображения поверхности $c$-Si, имплантированного четырьмя различными $D$ : $a-3.1 \cdot 10^{15}, b-3.1 \cdot 10^{16}, c-6.25 \cdot 10^{16}, d-$ $1.25 \cdot 10^{17} \mathrm{ions} / \mathrm{cm}^{2}$. Из рисунка видно, что на поверхности образцов присутствуют четкие округлые светлые области, расположенные на сером фоне. Известно, что на изображении, полученном с помощью SEM, области поверхности образца, которые состоят из атомов, характеризующихся более высоким атомным номером, будут выглядеть более светлыми по сравнению с областями, содержащими атомы с низким порядковым номером. Поэтому из рис. 1 следует, что светлые области соответствуют веществу, состоящему из более тяжелых атомов, например, наночастицам $\mathrm{Cu}$ или силицидам меди, а темные области соответствуют более легким атомам подложки $\mathrm{Si}$. Подобная картина фазового химического состава поверхности имплантированных об- 

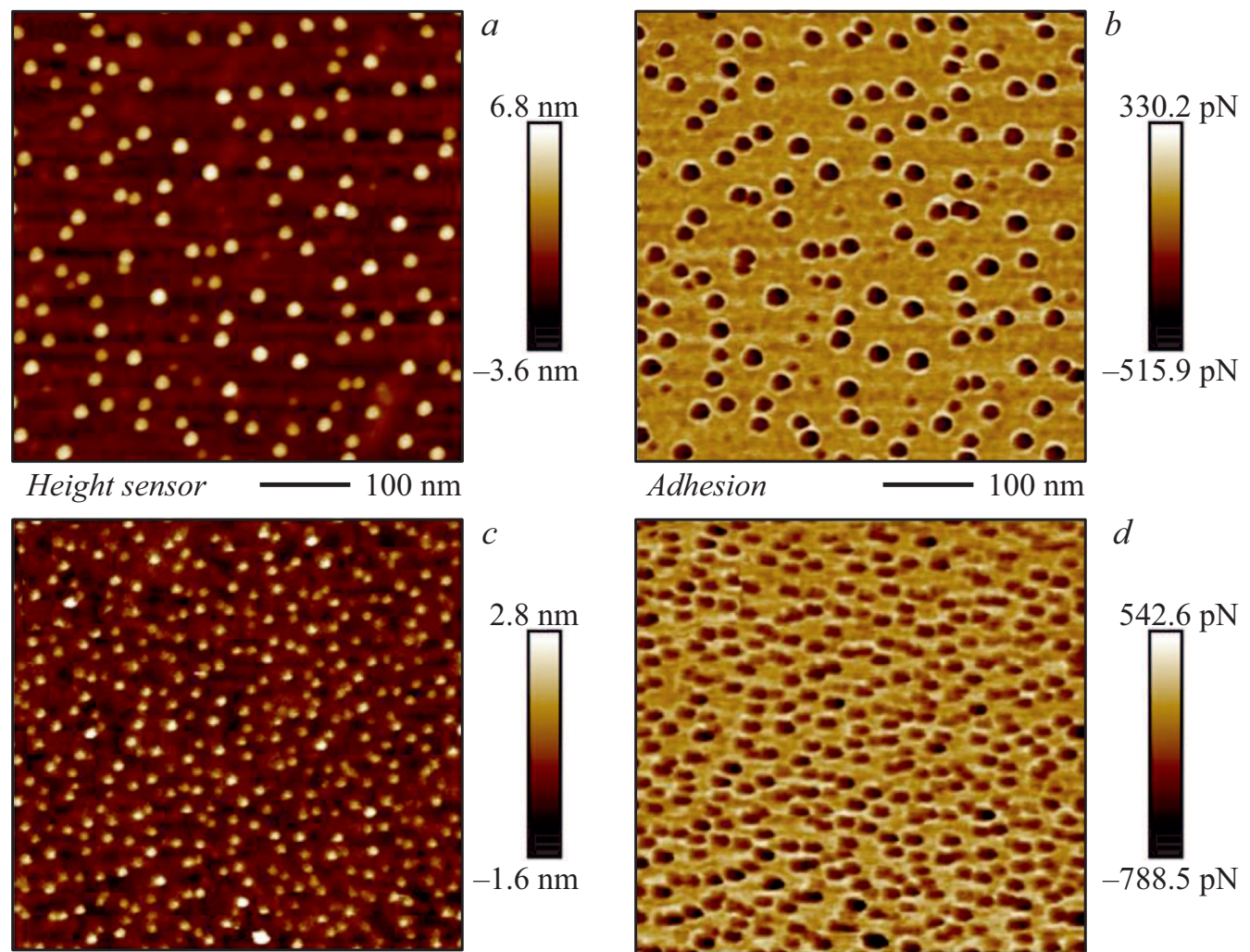

Adhesion $100 \mathrm{~nm}$
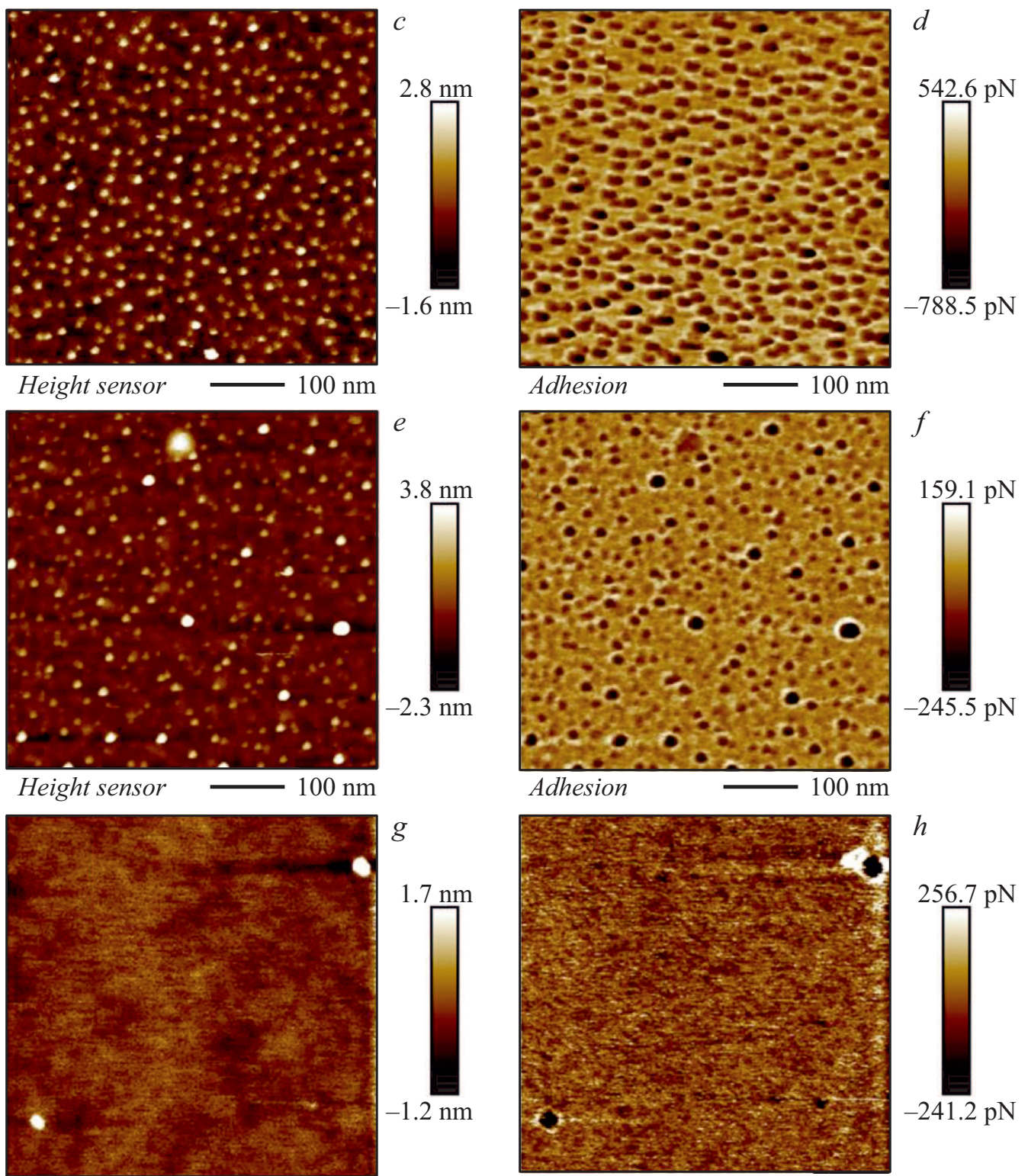

Height sensor

$100 \mathrm{~nm}$
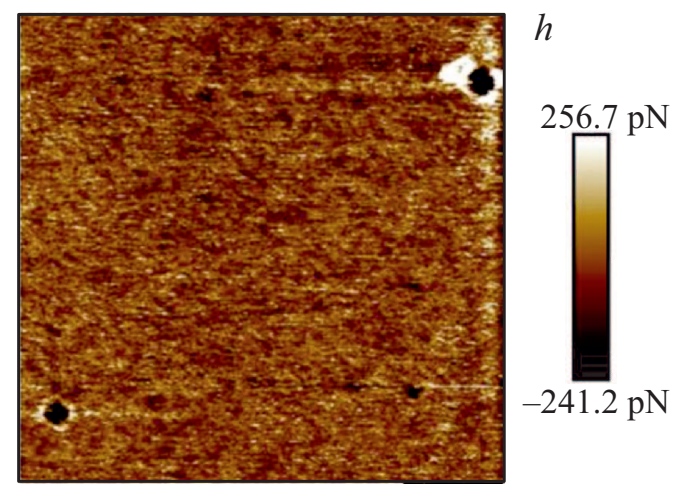

Adhesion

$100 \mathrm{~nm}$

Рис. 2. Изображения топографии $(a, c, e, g)$ и соответствующие им карты адгезии $(b, d, f, h)$ поверхности $\mathrm{Si}$, имплантированного ионами $\mathrm{Cu}^{+}$при $E=40 \mathrm{keV}$ и $D: 3.1 \cdot 10^{15}(a, b), 3.1 \cdot 10^{16}(c, d), 6.25 \cdot 10^{16}(e, f)$ и $1.25 \cdot 10^{17}$ ions $/ \mathrm{cm}^{2}(g, h)$. 
разцов наблюдается вплоть до $D=6.25 \cdot 10^{16}$ ions $/ \mathrm{cm}^{2}$. Однако дальнейшее увеличение $D$ имплантации приводит к уменьшению количества светлых участков, и при $1.25 \cdot 10^{17}$ ions $/ \mathrm{cm}^{2}$ наблюдается неравномерный, преимущественно темный фон, чередующийся с чуть более светлыми областями с нечеткими очертаниями. Следует отметить, что исходная подложка $\mathrm{Si}$ не загрязнена химическими примесями, а морфология ее поверхности является гладкой и однородной, как это было показано в работах $[3,7,8]$.

С целью более детальной оценки размеров и фазового химического отличия, сформированных имплантацией наночастиц от подложки $\mathrm{Si}$, были проведены SPM-измерения малых участков поверхности образцов в режиме количественного наномеханического картирования. На рис. 2 показаны SPM-изображения (левая колонка) поверхности образцов $\mathrm{Si}$, имплантированных ионами $\mathrm{Cu}^{+} \mathrm{c}$ различными $D$, а также соответствующие этим участкам карты адгезии (правая колонка). Распределение среднего размера наночастиц $\mathrm{Cu}$ для образцов $\mathrm{Si}$, имплантированных с $D=3.1 \cdot 10^{15}$ и $3.1 \cdot 10^{16}$ ions $/ \mathrm{cm}^{2}$, находится в достаточно узком диапазоне от 10 до $15 \mathrm{~nm}$ (рис. 2, $a, c$ ). При увеличении $D$ облучения до $6.25 \cdot 10^{16}$ ions $/ \mathrm{cm}^{2}$ pacпределение становится бимодальным с доминирующими размерами частиц $5 \mathrm{~nm}$ и $15 \mathrm{~nm}$ (рис. 2,e). При дальнейшем росте $D$ до $1.25 \cdot 10^{17} \mathrm{ions} / \mathrm{cm}^{2}$ наночастицы исчезают, а среднеквадратичная шероховатость поверхности становится $\sim 2 \mathrm{~nm}$ (рис. $2, g$ ). Различная цветовая гамма на картах адгезии (рис. 2) отражает локальные области поверхности, отличающиеся характеристической адгезией, а следовательно, различным фазовым химическим составом. Приведенные изображения (рис. $2, b, d, f)$ подтверждают заключения, полученные из SEM-результатов (рис. $1, a-c$ ), о наличии в имплантированных образцах двух различных фаз, одной, состоящей из наночастиц $\mathrm{Cu}$

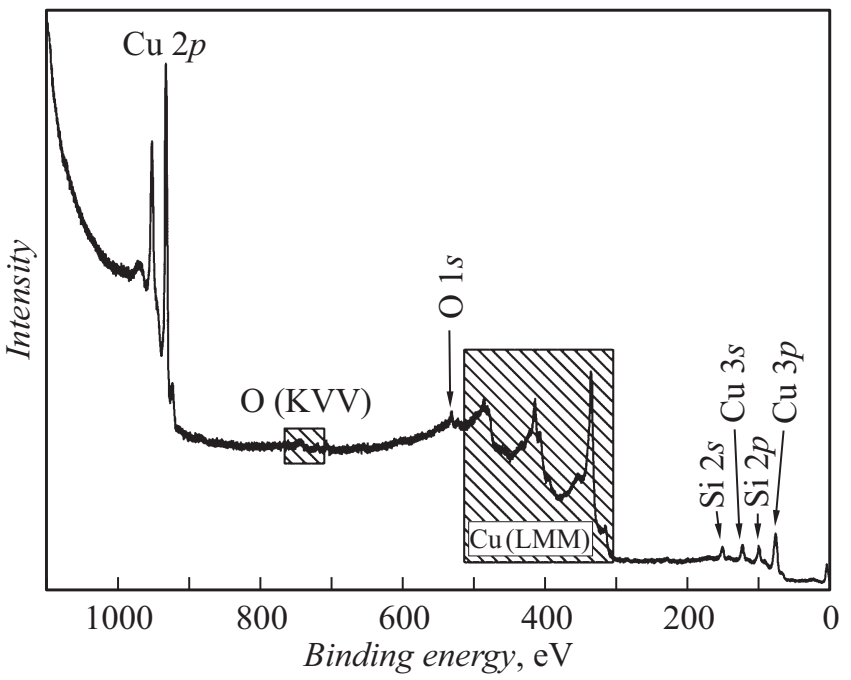

Рис. 3. Обзорный XPS-спектр, зарегистрированный для $\mathrm{Si}$, имплантированного ионами $\mathrm{Cu}^{+}$с $D=1.25 \cdot 10^{17}$ ions $/ \mathrm{cm}^{2}$. Спектр измерен после предварительной очистки поверхности ионами $\mathrm{Ar}^{+}$при $E=1 \mathrm{keV}$ в течение $600 \mathrm{~s}$.
Относительная концентрация $\mathrm{Cu}, \mathrm{O}, \mathrm{C}$ и $\mathrm{Si}$ в подложке $\mathrm{Si}$, имплантированной ионами $\mathrm{Cu}^{+}$с $E=40 \mathrm{keV}$ и $D=1.25 \cdot 10^{17}$ ions $/ \mathrm{cm}^{2}$. Соотношения концентраций получены с помощью метода XPS на последовательных этапах времени ионного травления $(t)$

\begin{tabular}{c|c|c|c|c}
\hline \multirow{2}{*}{$t, \mathrm{~s}$} & \multicolumn{4}{|c}{ Относительная концентрация элементов, at.\% } \\
\cline { 2 - 5 } & $\mathrm{Cu} 2 p$ & $\mathrm{O} 1 s$ & $\mathrm{C} 1 s$ & $\mathrm{Si} 2 p$ \\
\hline 0 & 0.89 & 43.859 & 22.144 & 33.108 \\
600 & 6.251 & 39.010 & 4.468 & 50.271 \\
1200 & 38.864 & 15.874 & - & 45.262 \\
1800 & 44.529 & 11.043 & - & 44.429 \\
2400 & 55.208 & 9.19 & - & 35.598
\end{tabular}

или силицидов $\mathrm{Cu}$ (темные круглые области), и другой, соответствующей подложке $\mathrm{Si}$ (светлый фон).

Для того, чтобы установить точный химический состав наночастиц, содержащих атомы $\mathrm{Cu}$, наблюдаемых на рис. 1 и 2, из возможных вариантов (металлический $\mathrm{Cu}, \alpha$-твердый раствор $\mathrm{Si}$ в $\mathrm{Cu}, \gamma-\mathrm{Cu}_{5} \mathrm{Si}$ пентамедисилицида, $\varepsilon-\mathrm{Cu}_{15} \mathrm{Si}_{4}$ и $\eta-\mathrm{Cu}_{3} \mathrm{Si}$ тримедисилицид [9]) был проведен анализ поверхности имплантированных образцов методами XPS и AES с применением техники профилирования (поверхностного травления) ионами $\mathrm{Ar}^{+}$.

С целью анализа химического состояния внедренной примеси $\mathrm{Cu}$ в $\mathrm{Si}$, для сравнения были измерены обзорный и подробный (для фотоэлектронов $\mathrm{Cu} 2 p$ ) спектры от $\mathrm{Cu}$ фольги (99.99\% чистоты). Энергетическое положение пика $\mathrm{Cu} 2 p_{3 / 2}$ от чистой меди с энергией связи $932.5 \mathrm{eV}$ служило для калибровки всех зарегистрированных XPS-спектров.

На рис. 3 приведен обзорный XPS-спектр для подложки $\mathrm{Si}$, имплантированной с $D=1.25 \cdot 10^{17} \mathrm{ions} / \mathrm{cm}^{2}$, после ионного травления в течении $t=600 \mathrm{~s}$, который показал наличие энергетических пиков, характерных для $\mathrm{Cu}, \mathrm{Si}, \mathrm{O}$ и $\mathrm{C}$ в пределах разрешающей способности метода XPS (0.1 at.\%). По-видимому, интенсивный сигнал от углерода обнаруживается в спектре образца вследствие загрязнения его поверхности органическими соединениями (осадок в виде углеводородов) при использовании масляных вакуумных насосов во время ионной имплантации. После более длительного мягкого травления ионами $\mathrm{Ar}^{+}$при $E=1 \mathrm{keV}$ интенсивность углеродной линии, характеризующей загрязнение, быстро уменьшается и пропадает (см. таблицу). Поэтому в дальнейших анализах спектров линия углерода не рассматривалась и не учитывалась.

Дополнительно, после каждого этапа травления, для $\mathrm{Cu}, \mathrm{Si}$ и O были зарегистрированы подробные спектры фотоэлектронов внутренних оболочек $\mathrm{Cu} 2 p, \mathrm{Si} 2 p$ и $\mathrm{O} 1 s$, a также получены соотношения их концентраций в атомных процентах (at.\%), рассчитанные с помощью интегральной интенсивности фотоэлектронных спектров, скорректированных на соответствующие факторы элементной чувствительности (см. таблицу). 

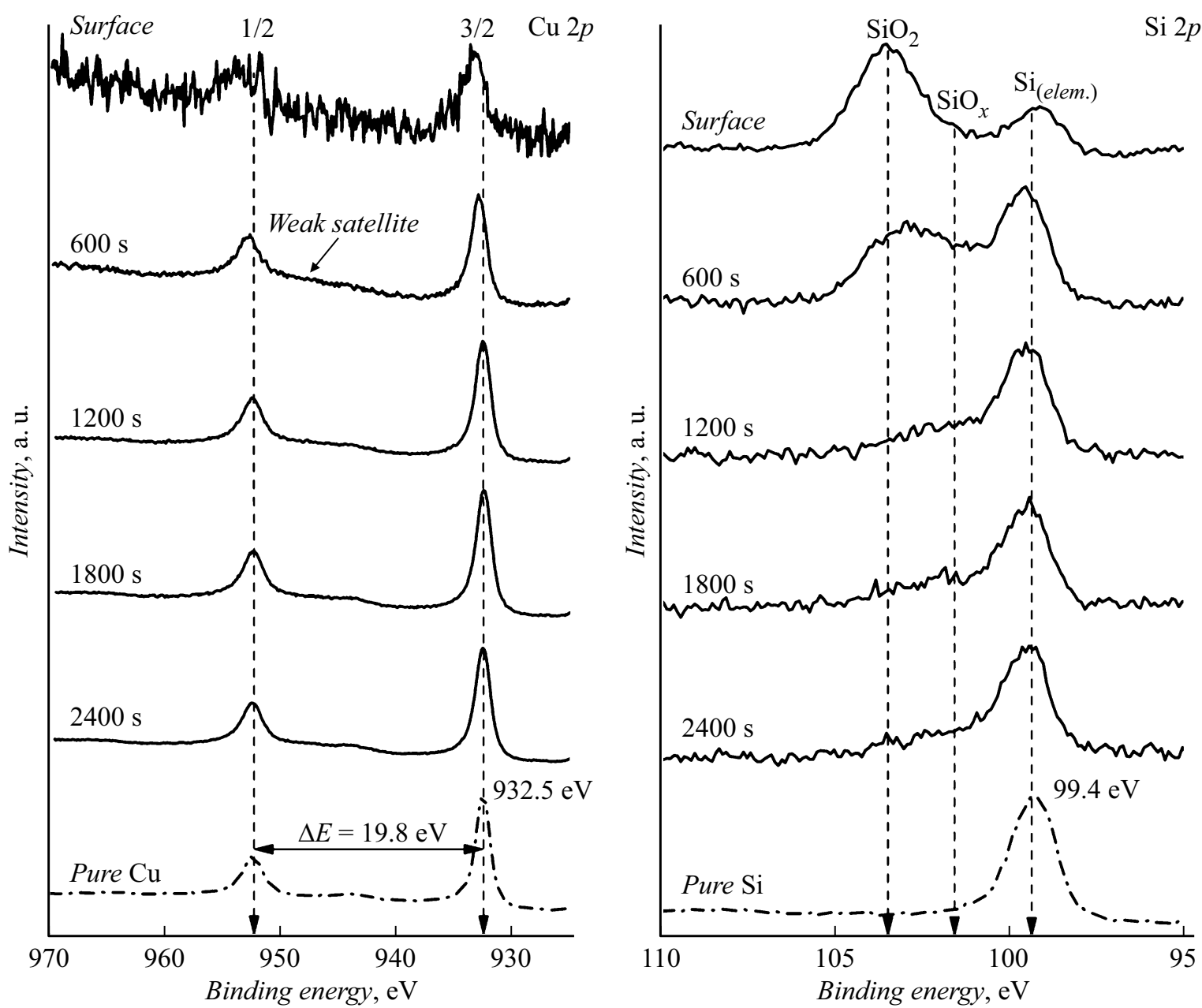

Рис. 4. Картина эволюции формы линии XPS в зависимости от времени ионного травления $t$ для спектров фотоэлектронов Сu $2 p$ (левая панель) и $\mathrm{Si} 2 p$ (правая панель), зарегистрированных на различных этапах (глубине образца) травления ионами Аr ${ }^{+}$образца $\mathrm{Si}$, имплантированного ионами $\mathrm{Cu}^{+}$с $D=1.25 \cdot 10^{17}$ ions $/ \mathrm{cm}^{2}$.

На рис. 4 представлена эволюция формы линий спектров $\mathrm{Cu} 2 p$ и $\mathrm{Si} 2 p$ фотоэлектронов, зарегистрированных на различном этапе травления в имплантированном образце при $D=1.25 \cdot 10^{17}$ ions $/ \mathrm{cm}^{2}$. Положение основного пика $\mathrm{Cu}$ соответствует энергии связи $\sim 933 \mathrm{eV}$. В результате травления ионами $\mathrm{Ar}^{+}$интенсивность пика резко возрастает, что говорит об увеличении концентрации $\mathrm{Cu}$. Этот пик сдвигается по спектру к энергии связи $932.5 \mathrm{eV}$, что соответствует энергетическому положению связи $\mathrm{Cu}-\mathrm{Cu}$ в металлическом состоянии $\left(\mathrm{Cu}^{0}\right)$ [10]. Известно, что XPS-анализ $\mathrm{Cu}$ и разделение между пиками для валентности $\mathrm{Cu}^{0}$ и $\mathrm{Cu}^{1+}$ являются достаточно сложной задачей, поскольку разница в величинах энергий связи соответствующих валентностей $\mathrm{Cu}$ для $\mathrm{Cu} 2 p$ спектра составляет $0.2 \mathrm{eV}$, в то время как ошибка определения энергетического положения XPS-пика составляет $0.1 \mathrm{eV}[11]$. С достаточно большой уверенностью можно утверждать, что $\mathrm{CuO}$ с валентностью $\mathrm{Cu}^{2+}$ отсутствует, так как чувствительный к этой степени окисления $\mathrm{Cu}$ сателлитный пик $(943 \mathrm{eV})$ не наблюдается в подробных $\mathrm{Cu} 2 p$-спектрах, в отличие от, например, работы [12], где данный сателлитный пик для двухвалентной меди $\mathrm{CuO}$ присутствует при энергии связи $943 \mathrm{eV}$.

Для того, чтобы убедиться в возможном присутствии $\mathrm{Cu}_{2} \mathrm{O}$ с валентностью $\mathrm{Cu}^{1+}$, производилась регистрация подробных спектров оже-линии $\mathrm{Cu}$ CuLMM, по которым определялось положение кинетической энергии основной оже-линии $\mathrm{L}_{3} \mathrm{VV}$. Зная значение энергии связи для фотоэлектронов $\mathrm{Cu} 2 p E_{b}(932.5 \mathrm{eV})$ и величину кинетической энергии для основной оже-линии CuLMM $E_{k}$ $(918.5 \mathrm{eV})$, можно рассчитать оже-параметр $\alpha$, чувствительный к степени окисления $\mathrm{Cu}$. Тогда по определению $\alpha=E_{b}(\mathrm{Cu} 2 p)+E_{k}\left(\mathrm{~L}_{3} \mathrm{VV}\right)=1851.0 \mathrm{eV}$ величина параметра $\alpha$ соответствует $\mathrm{Cu}$ с валентностью $\mathrm{Cu}^{0}$. Данное обстоятельство указывает на то, что имплантированная примесь $\mathrm{Cu}$ находится в металлическом состоянии, т.е. в виде наночастиц $\mathrm{Cu}$.

При анализе энергетического спектра $\mathrm{Si}$ наблюдается два ярко выраженных пика фотоэлектронов с энергиями связи 103.5 и $99.4 \mathrm{eV}$ (рис. 4, правая панель). Спектр линии кислорода $\mathrm{O} 1 s$ также регистрировался, данные по концентрации для различных этапов травления при- 


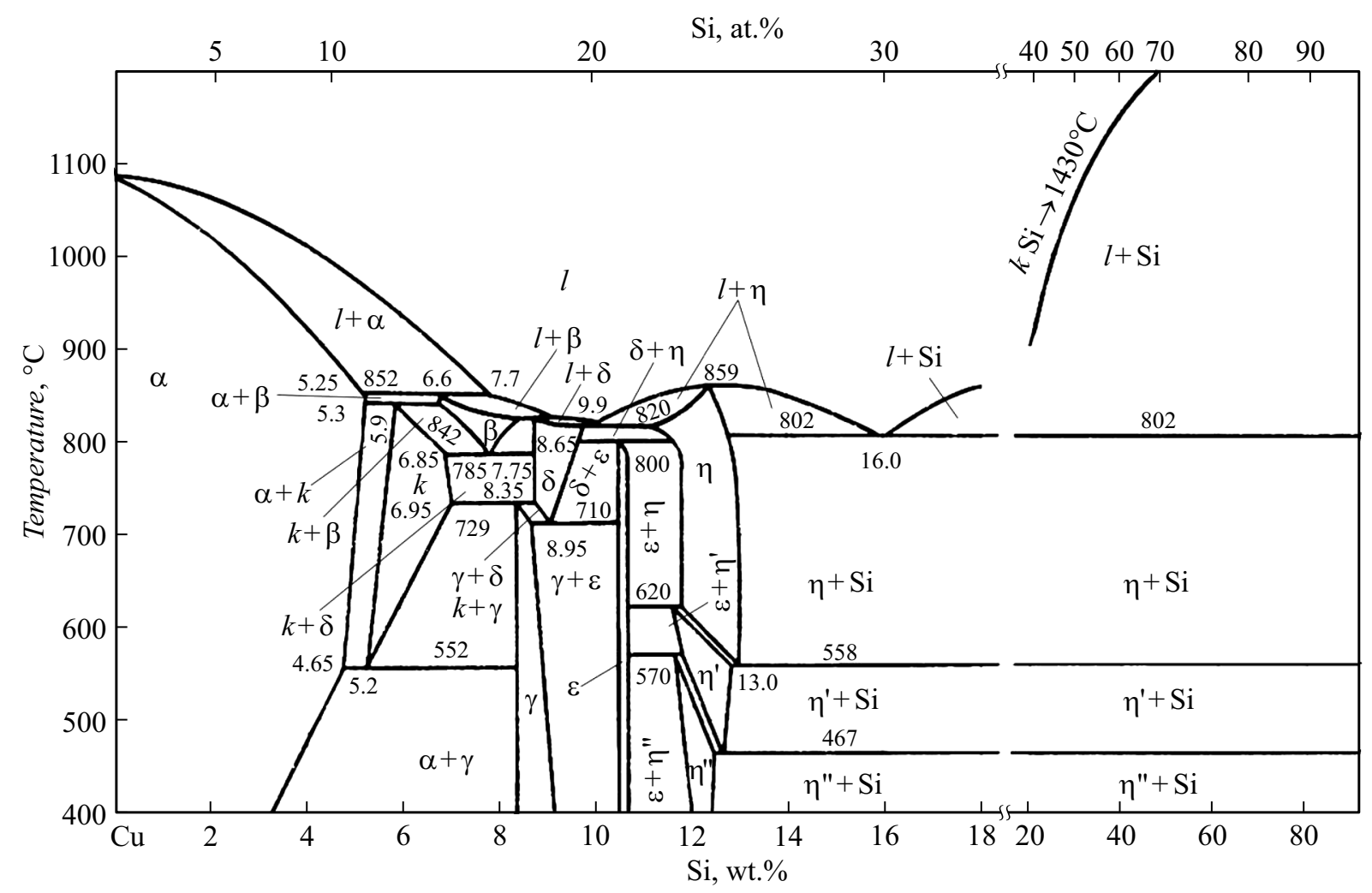

Рис. 5. Фазовая диаграмма бинарной системы $\mathrm{Si}-\mathrm{Cu}[9]$.

ведены в таблице. Согласно атласу фотоэлектронных спектров, первый пик $(103.5 \mathrm{eV})$ соответствует энергетическому положению для атомов $\mathrm{Si}$ с валентностью $\mathrm{Si}^{4+}$ в соединении диоксида кремния $\left(\mathrm{SiO}_{2}\right)$, а второй пик с энергией связи $99.4 \mathrm{eV}$ - элементарному кремнию $\left(\mathrm{Si}^{0}\right)$. C увеличением времени ионного травления и, следовательно, глубины XPS-анализа интенсивность первого пика падает и сдвигается в сторону меньших энергий. Такое поведение формы и интенсивности пика говорит о том, что в облученном слое присутствует смешанный оксид кремния $\mathrm{Si}_{1-x} \mathrm{O}_{x}$, а не только $\mathrm{SiO}_{2}$.

После нескольких этапов травления первый пик $(103.5 \mathrm{eV})$ полностью исчезает, и у фотоэлектронов $\mathrm{Si} 2 p$ в спектре наблюдается только один интенсивный пик при энергии связи $99.4 \mathrm{eV}$. Поскольку при данных режимах ионного травления образца и вследствие того, что эффективность распыления атомов О выше, чем у $\mathrm{Si}$, потенциально возможна ситуация, когда образец лишится О. Однако, этого не происходит (процесс селективного распыления отсутствует), и поэтому становится очевидным, что $\mathrm{SiO}_{2}$ присутствует только на поверхности исследованного образца и, согласно картине эволюции, исчезает после нескольких этапов травления.

Таким образом, имплантация ионами $\mathrm{Cu}^{+}$с использованием относительно больших $D$ порядка $10^{16}$ ions $/ \mathrm{cm}^{2}$ приводит к образованию дефектов в облучаемой матрице $c$-Si c последующей ее аморфизацией. Накопление примеси $\mathrm{Cu}$ в $\mathrm{Si}$ сверх предела растворимости приводит к зарождению и росту наночастиц $\mathrm{Cu}$, затем к их выходу на поверхность облучаемой подложки в результате ее распыления, как это наблюдалось ранее для различных имплантированных материалов [3,13]. В то же время, как следует из полученных SEM- и SPM-данных (рис. 1, $d$ ) и (рис. $2, g, h$ ), наночастицы $\mathrm{Cu}$ в имплантированном $\mathrm{Si}$ не наблюдаются для образца, имплантированного с более высокой $D=1.25 \cdot 10^{17}$ ions $/ \mathrm{cm}^{2}$. Поэтому очевидно, что наночастицы $\mathrm{Cu}$, сформированные при меньшей $D$, при ее увеличении разрушаются.

Как было указано в работах [6,14], атомы $\mathrm{Cu}$ способны составлять с атомами $\mathrm{Si}$ различные химические соединения такие, как $\alpha$-твердый раствор $\mathrm{Si}$ в $\mathrm{Cu}, \gamma-\mathrm{Cu}_{5} \mathrm{Si}$ пентамедисилицида, $\varepsilon-\mathrm{Cu}_{15} \mathrm{Si}_{4}$ и $\eta^{\prime \prime}-\mathrm{Cu}_{3} \mathrm{Si}$ тримедисилицида. Фазовая диаграмма бинарной системы $\mathrm{Cu}-\mathrm{Si}$ из работ $[6,14]$ приведена на рис. 5. Можно предположить, что с увеличением длительности ионной имплантации (повышения $D$ ), при разрушении наночастиц $\mathrm{Cu}$ образуются какие-либо бинарные соединения $\mathrm{Cu}-\mathrm{Si}$ из перечисленных выше. Причиной, приводящей к фазовому изменению $\mathrm{Cu}$-соединений, вероятнее всего, является заметный нагрев имплантированного образца свыше $100^{\circ} \mathrm{C}$, который, как известно, неизбежно возникает при длительном облучении на ионном ускорителе. Как было показано выше, XPS-измерения, вследствие ограничения по энергетическому разрешению, не могут выявить возможный тип бинарного $\mathrm{Cu}-\mathrm{Si}$, образующегося при высокой $D$. В частности, например, согласно литературным 

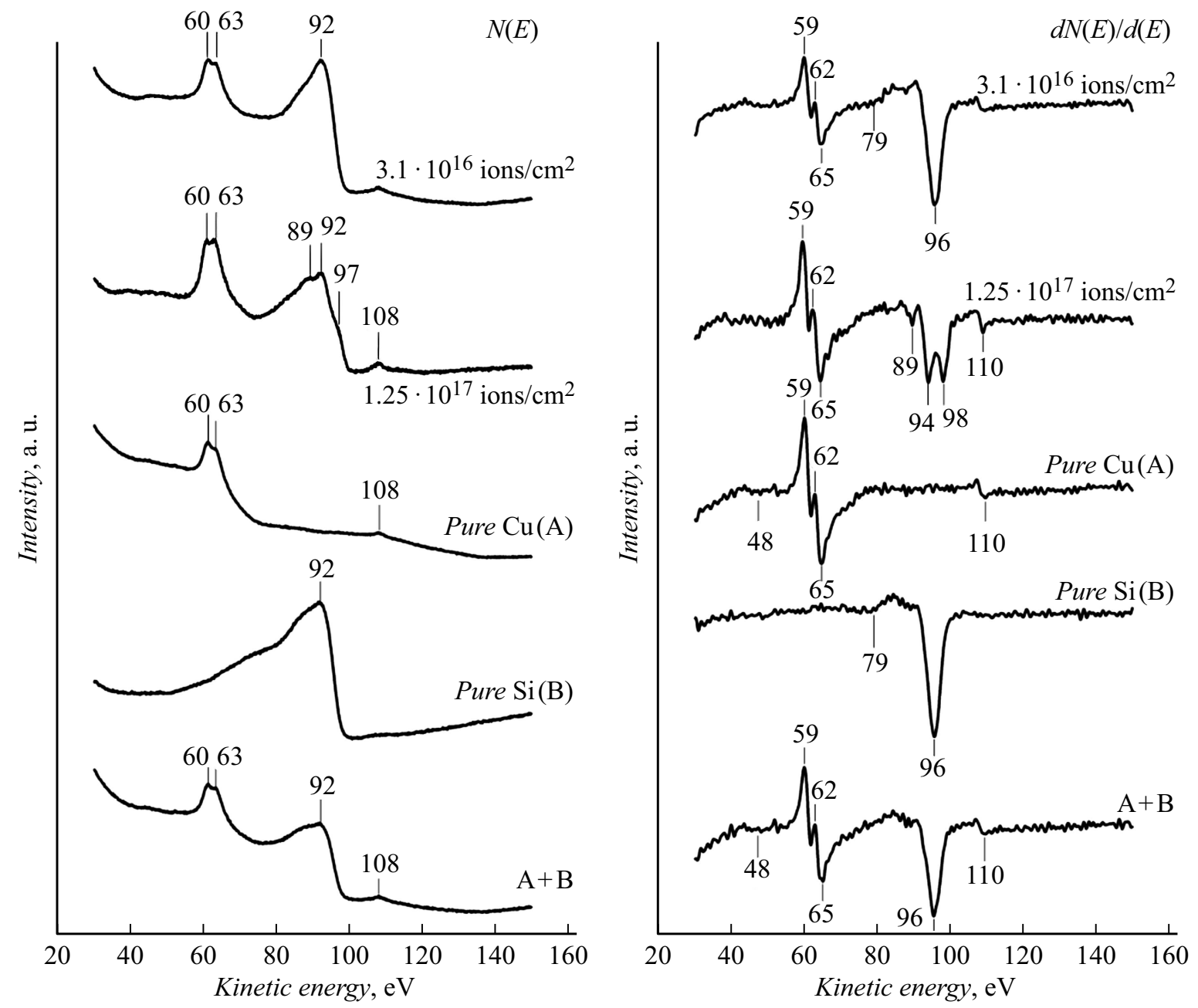

Рис. 6. Интегральная (левая панель) и соответствующая ей дифференциальная (правая панель) формы оже-спектров, зарегистрированных на подложках $\mathrm{Si}$, имплантированных ионами $\mathrm{Cu}^{+}$при $D=3.1 \cdot 10^{16}$ и $1.25 \cdot 10^{17}$ ions $/ \mathrm{cm}^{2}$, а также фольге $\mathrm{Cu}(\mathrm{A})$, подложки $\mathrm{Si}(\mathrm{B})$ и их сумма $(\mathrm{A}+\mathrm{B})$.

данным [15], исследования соединения $\mathrm{Cu}_{3} \mathrm{Si}$ методом XPS показывают, что $\mathrm{Cu}$ и $\mathrm{Si}$ находятся в элементном (не связанном) состоянии с валентностями $\mathrm{Cu}^{0}$ и $\mathrm{Si}^{0}$ и энергиями связи 932.5 и $99.4 \mathrm{eV}$ соответственно. В работе [15] также сказано, что более эффективным методом идентификации соединений $\mathrm{Si}-\mathrm{Cu}$, в частности, отличия $\eta$-фазы $\left(\mathrm{Cu}_{3} \mathrm{Si}\right)$ от других силицидов $\mathrm{Cu}$, является AES с применением подробного анализа формы оже-линии $\mathrm{Si}\left(\mathrm{L}_{2.3} \mathrm{VV}\right)$. Поэтому, в настоящей работе образцы $\mathrm{Si}$, имплантированные ионами $\mathrm{Cu}^{+}$при $D=3.1 \cdot 10^{16}$ и $1.25 \cdot 10^{17}$ ions $/ \mathrm{cm}^{2}$, были исследованы методом AES. Peгистрация оже-линий $\mathrm{Si}\left(\mathrm{L}_{2.3} \mathrm{VV}\right)$ и $\mathrm{Cu}\left(\mathrm{M}_{2.3} \mathrm{~N}_{4.5} \mathrm{~N}_{4.5}\right)$ для образца с $D=1.25 \cdot 10^{17} \mathrm{ions} / \mathrm{cm}^{2}$ проводилась без его эвакуации на воздух, непосредственно после последнего этапа травления $(t=2400 \mathrm{~s})$. Дополнительно, для сравнения, были зарегистрированы оже-спектры для чистой фольги $\mathrm{Cu}$ и монокристаллической подложки $c-\mathrm{Si}$.

На рис. 6 показаны оже-спектры $\mathrm{Cu}$ и $\mathrm{Si}$ в интегральной (левая панель) и дифференциальной (правая панель) формах. Был проведен анализ их формы, а энер- гетические положения пиков сопоставлены с данными атласов оже-электронных спектров [16] и работы [15]. Из зарегистрированных оже-спектров было установлено, что имплантация ионами $\mathrm{Cu}^{+}$при $D=3.1 \cdot 10^{16} \mathrm{ions} / \mathrm{cm}^{2}$ не приводит к образованию какой-либо фазы силицида $\mathrm{Cu}$, что хорошо согласуется с данными XPS по образованию наночастиц $\mathrm{Cu}$. На интегральном оже-спектре хорошо различим пик при $92 \mathrm{eV}$, отвечающий за $\mathrm{Si}$ в элементарном состоянии, а также прослеживаются два пика при 60 и $63 \mathrm{eV}$, характерных для металлической меди. На дифференциальном спектре присутствуют два синглета при энергиях 79 и $96 \mathrm{eV}$, соответствующие элементарному $\mathrm{Si}$, а также пик при $65 \mathrm{eV}$, относящийся к металлической меди.

На оже-спектре образца $\mathrm{Si}$, имплантированного с $D=1.25 \cdot 10^{17} \mathrm{ions} / \mathrm{cm}^{2}$, помимо линий 60 и $63 \mathrm{eV}$, также обнаруживается плечо при энергии связи $97 \mathrm{eV}$, что является характерной особенностью спектра $\left(\mathrm{L}_{3} \mathrm{VV}\right) \mathrm{Si}$ в соединении $\mathrm{Cu}_{3} \mathrm{Si}$. В дифференциальной форме спектра это плечо дает дублет при энергиях 94 и $98 \mathrm{eV}$. Спектр 
с аналогичной формой линии наблюдался также и в работе [15] для $\eta$-фазы $\mathrm{Cu}_{3} \mathrm{Si}$.

Таким образом, механизмы зарождения, разрушения наночастиц меди и образования силицидов при росте дозы облучения можно представить следующим образом. Имплантация с дозой $D=3.1 \cdot 10^{15} \mathrm{ions} / \mathrm{cm}^{2}$ уже приводит к образованию наночастиц $\mathrm{Cu}$ в приповерхностной области торможения ионов меди, в которой превышен порог равновесной растворимости меди в кремнии, и их выходу на поверхность за счет распыления кремния. При дальнейшем росте дозы, заглубленный слой кремния под слоем торможения постепенно аморфизируется, что приводит к уменьшению его теплопроводности на один-два порядка (согласно работам [17-20], теплопроводность аморфного кремния лежит в интервале $1.5-2.6 \mathrm{~W} /(\mathrm{m} \cdot \mathrm{K})$, тогда как у кристаллического кремния она составляет $146-152 \mathrm{~W} /(\mathrm{m} \cdot \mathrm{K}))$. В результате, с ростом дозы начинается распыление вышедших на поверхность наночастиц меди, а усиливающийся разогрев приповерхностного слоя имплантируемого образца приводит к повышенному оттоку атомов меди вглубь за счет термически стимулированной диффузии (см. [21], рис. $1, b, c$ и рис. 2,c,e), и к уменьшению скорости роста наночастиц меди. При продолжении облучения и росте толщины аморфизированного и „загрязненного“ имплантом заглубленного слоя температура области торможения над ним растет, и имплантируемая медь вступает в реакцию с кремнием, рост наночастиц меди прекращается. В результате, ко времени достижения дозы $D=1.25 \cdot 10^{17}$ ions $/ \mathrm{cm}^{2}$ все вышедшие на поверхность наночастицы меди распыляются, а ионы меди, оставшиеся в образце, оказываются в основном в виде силицида $\mathrm{Cu}_{3} \mathrm{Si}$, согласно нашему анализу спектров рентгеновских фото- и оже-электронов. По данным работы [22], твердотельная реакция меди и кремния с образованием $\mathrm{Cu}_{3} \mathrm{Si}$ происходит уже при температуре от $230^{\circ} \mathrm{C}$ и выше, до которой может разогреваться приповерхностный слой толщиной несколько десятков нанометров. Вероятно, часть примеси меди может оставаться и в элементарном металлическом или атомарном состоянии, однако это находится за пределами чувствительности нашего оборудования.

\section{Выводы}

В работе приведены результаты исследований структуры и фазового химического состава поверхности подложек $\mathrm{Si}$, имплантированных ионами $\mathrm{Cu}^{+}$с $E=40 \mathrm{keV}$ и $D$ в диапазоне от $3.1 \cdot 10^{15}$ до $1.25 \cdot 10^{17} \mathrm{ions} / \mathrm{cm}^{2}$. Показано, что при облучении с $D$ до $6.25 \cdot 10^{16} \mathrm{ions} / \mathrm{cm}^{2}$, на поверхности облученной подложки $\mathrm{Si}$ образуются металлические наночастицы $\mathrm{Cu}$. При имплантации $\mathrm{Cu}^{+}$и дальнейшем росте $D \geq 1.25 \cdot 10^{17} \mathrm{ions} / \mathrm{cm}^{2}$ в облученном слое $\mathrm{Si}$ формируется $\eta$-фаза $\mathrm{Cu}_{3} \mathrm{Si}$ как результат его нагрева при длительном облучении.

\section{Благодарности}

Исследования образцов методами XPS и AES выполнены с использованием оборудования Федерального центра коллективного пользования физико-химических исследований Казанского федерального университета. А.И. Гумаров и Л.Р. Тагиров благодарят Программу повышения конкурентоспособности КФУ за поддержку их работы.

\section{Финансирование работы}

Работа выполнена при финансовой поддержке Российского научного фонда, проект № 17-12-01176 „Формирование слоев пористого кремния и германия с металлическими наночастицами методом ионной имплантации“.

\section{Конфликт интересов}

Авторы заявляют, что у них нет конфликта интересов.

\section{Список литературы}

[1] Bandarenko H., Prischepa S.L., Fittipaldi R., Vecchione A., Nenzi P., Balucani M., Bondarenko V. // Nanoscale Res. Lett. 2013. Vol. 8. N 85. P. 1-8. https://doi.org/10.1186/1556-276X-8-85

[2] Сочкая Н.В., Долгих О.В., Кашкаров В.М., Леньшин А.С., Котлярова Е.А., Макаров С.В. // Сорбционные и хромотографические просессы. 2009. Т. 9. Вып. 5. С. 643-652. http://www.sorpchrom.vsu.ru/articles/20090507.pdf

[3] Степанов А.Л., Нужсин В.И., Воробьев В.В., Рогов А.М. Формирование слоев пористого кремния и германия с металлическими наночастицами. Казань: Изд-во ФИЦ КазНЦ РАН, 2019. 188 c.

[4] Nastasi M., Mayer J., Hirvonen J. Ion-Solid Interactions: Fundamentals and Applications (Cambridge Solid State Science Series). Cambridge: Cambridge University Press. 1996. DOI: $10.1017 / \mathrm{CBO} 9780511565007$

[5] Cullis A.G., Webber H.C., Poate J.M., Chew N.G. // J. Microsc. 1980. Vol. 118. N. 1. P. 41-49. https://doi.org/10.1111/j.1365-2818.1980.tb00244.x

[6] Walton J., Wincott P., Fairley N., Carrick A. Peak fitting with CasaXPS: a Casa pocket book, Accofyte Sci., Knutsford UK, 2010. ISBN 978-0954953317.

[7] Воробьев В.В., Рогов А.М., Осин Ю.Н., Нужсдин В.И., Валеев В.Ф., Эйдельман К.Б., Табачкова Н.Ю., Ермаков М.А., Степанов А.Л. // ЖТФ. 2019. Т. 89. Вып. 2. C. $226-234$. DOI: $10.21883 /$ JTF.2019.02.47075.145-18

[8] Stepanov A.L., Trifonov A.A., Osin Y.N., Valeev V.F., Nuzhdin V.I. // Optoelectron. Adv. Mater. Rapid Commun. 2013. Vol. 7. N 9-10. P. 692-697.

[9] Бучин Э.Ю., Наумов В.В., Васильев С.В. // ФТП. 2019. T. 53. C. $418-422$.

[10] NIST X-Ray Photoelectron Spectroscopy Database, NIST Standard Reference Database Number 20, Version 4.1, National Institute of Standards and Technology, Gaithersburg, Maryland, USA, 2000, http://dx.doi.org/10.18434/T4T88K 
[11] Adonin N.Y., Prikhod'ko S.A., Shabalin A.Y., Prosvirin I.P., Zaikovskii V.I., Kochubey D.I., Zyuzin D.A., Parmon V.N., Monin E.A., Bykova I.A., Martynov P.O., Rusakov S.L., Storozhenko P.A. // J. Catal. 2016. V. 338. P. 143-153. https://doi.org/10.1016/j.jcat.2016.03.012

[12] Sharma A.K., Gupta S.K. // J. Catal. 1985. Vol. 93. N 1. P. $68-$ 74. https://doi.org/10.1016/0021-9517(85)90151-4

[13] Stepanov A.L., Vorobev V.V., Rogov A.M., Nuzhdin V.I., Valeev V.F. // Nuclear Inst. Methods Phys. Res. B. 2019. Vol. 457. P. 1-3. https://doi.org/10.1016/j.nimb.2019.07.020

[14] Massalski T.B., Okamoto H. Binary Alloy Phase Diagrams, 2nd Ed. Materials Park, Ohio:ASM International.1990.

[15] Banholzer W.F., Burrell M.C. // Surf. Sci. 1986. Vol. 176. N 1-2. P. 125-133.

[16] Childs K.D. Handbook of Auger electron spectroscopy: a book of reference data for identification and interpretation in Auger electron spectroscopy. Physical Electronics. 1995.

[17] Goldsmid H.J., Kaila M.M., Paul G.L. // Phys. Stat. Sol. (A). 1983. Vol. 76. P. K31-K33. https://doi.org/10.1002/pssa.2210760156

[18] Wada H., Kamijoh T. // Jpn. J. Appl. Phys. 1996. Vol. 35. P. L648-L650. https://doi.org/10.1143/JJAP.35.L648

[19] Moon S., Hatano M., Lee M., Grigoropoulos C.P. // Intern. J. Heat Mass Trans. 2002. Vol. 45. P. 2439-2447.

[20] Moon S.-J., Choi. J.H. // J. Nanosci. Nanotech. 2013. Vol. 13. P. 6362-6366. https://doi.org/10.1166/jnn.2013.7712

[21] Ачкеев А.А., Хайбуллин Р.И., Тагиров Л.Р., Mackova А., Hnatowicz V., Cherkashin N. // ФTT. 2011. T. 53. C. 508517. [Phys. Sol. State. 2011. Vol. 53. P. 543-553.]. https://journals.ioffe.ru/articles/viewPDF/1360

[22] Gao X.-X., Li T.-J., Li G.-P., Cao B. // Nucl. Instr. Meth. Phys. Res. B. 2008. Vol. 266. P. 2572-2575. https://doi.org/10.1016/j.nimb.2008.03.082 